\title{
STUDIES IN THE PHYSIOLOGY OF BLOOD VESSELS IN MAN. APPARATUS AND METHODS. II. A METHOD FOR THE DETERMINATION OF THE VOLUME OF THE SOFT TISSUE ABOUT THE TERMINAL PHALANX OF THE HUMAN FINGER ${ }^{1}$
}

\author{
By W. A. SODEMAN \\ (From the Department of Medicine, Tulane University of Louisiana, New Orleans)
}

(Received for publication May 4, 1937)

For quantitative studies in the physiology of the peripheral blood vessels of the human which are under way in this laboratory the soft tissues of the terminal part of the finger have been found particularly satisfactory. This communication deals with a method for estimating in the living human the volume of soft tissues in that portion of the finger which, for lack of a better term, we call the finger tip.

The method consists of a determination of the total volume of the finger tip, an estimation of the bone volume and a calculation of the soft tissue volume by difference. The finger nail was included in the soft tissue volume.

The finger tip has been defined, in terms of skin markings, as that portion of the finger distal to a plane passing through the center of the dorsal and palmar skin crease at the distal interphalangeal joint. This plane passes through the distal end of the second phalanx.

The total volume of this portion of the finger, when held at heart level, was determined by making a cast of the part in dental stone. ${ }^{2}$ The setting expansion of the dental stone is only 0.13 per cent. The mixture, as a free flowing fluid, moulded itself about the finger without deforming pressure and accurately reproduced minute details of skin surface. The open end of the cast was then ground down to the desired plane with a file and emery cloth and overfilled with mercury. By pressing a glass plate firmly over the open end of the cast the excess mercury was forced to escape. The remaining mercury was then transferred to a microburette by means of a pipette, and measured to one cubic millimeter.

1 Aided by grants from The David Trautman Schwartz Fund, The Josiah Macy, Jr. Foundation, and The Committee on Scientific Research of the American Medical Association.

2 The proprietary product Investone was used.
Repeated determinations of the volume of one finger tip over a period of two days with sixteen independently made casts gave volumes varying from 4.398 to 4.492 cc. Statistical analysis of these sixteen trials gave a mean of $4.453 \pm 0.005$ cc., a standard deviation of 0.027 and a probable error of 0.018 .

To determine bone volume a formula was derived from data on thirty-three sets of phalanges covering the range of sizes seen in our subjects. Phalangeal bones of the second, third and fourth fingers were mounted upon wooden blocks with paraffin to simulate the bony anatomical relationships in the living subject. A level corresponding to the plane of the skin markings was laid off with radiopaque foil and anteroposterior and lateral roentgenograms taken at a tube distance of six feet. From these plates the areas of the segments of the bone shadows desired were obtained with a planimeter. The joint space was included in the measured area. Its borders were determined in the anteroposterior view from anatomical markings clearly shown on the roentgenogram. In the lateral view, because of the lack of anatomical landmarks, projections of the outline of the terminal phalanx to the shadow of the second phalanx were used. Lengths of these segments were determined to $0.1 \mathrm{~mm}$. by use of a caliper, millimeter scale, and lens. By dividing lateral area by length a figure termed the "mean thickness" resulted. Anteroposterior area multiplied by mean thickness resulted in a trial calculated volume.

True volumes of the bones were determined by use of dental stone casts in a manner similar to that used for total finger volume. In these determinations, however, split casts were used. The thirty-three volumes varied from 0.341 to 1.183 cc. Percentage differences between the measured volumes and the trial calculations were deter- 


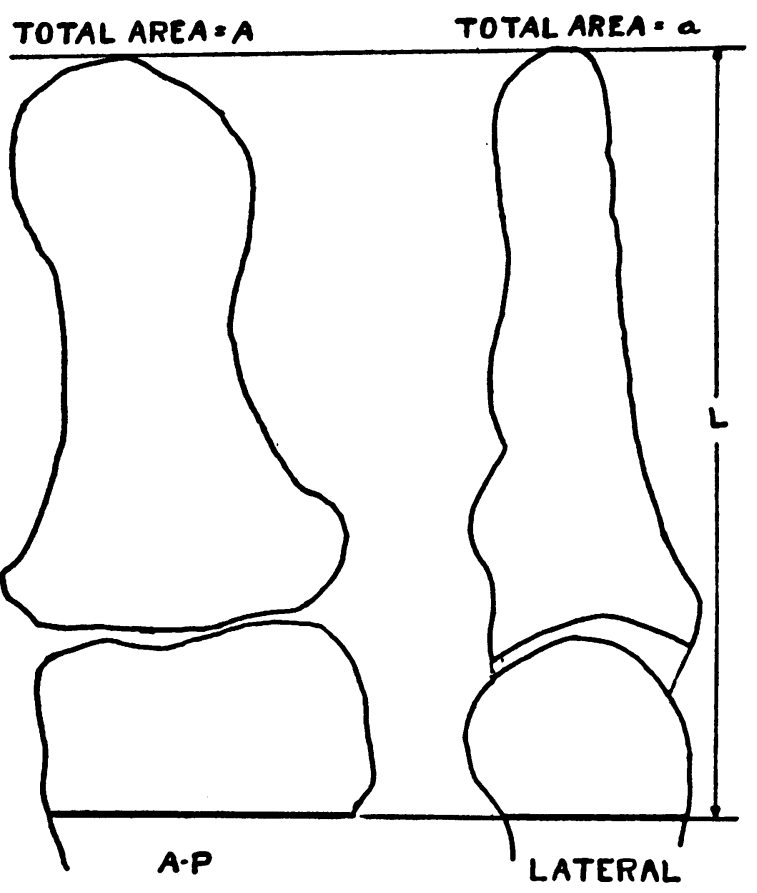

$A \cdot \frac{a}{L} \cdot 0.955=$ BONE VOLUME $\pm 1.44 \%$

Fig. 1.

Diagram Illustrating the Bone Segments MeasuREd in the Determination of the Bone Volume of THE Finger Tip

mined in each case and these differences analyzed statistically. Differences varied from 0.0 per cent to 8.6 per cent, the calculations being the higher values. Mean difference was $4.50 \pm 0.24$ per cent, the probable error 1.44 , and the standard deviation 2.12 for the frequency distribution. Application of these differences to a formula for bone volume resulted in the following relationship : $0.955 \times A \times \frac{a}{L}=$ volume \pm 1.44 per cent where $A=A P$ area, $a=$ lateral area, and $L=$ length.

In applying this formula to the living finger one must obtain accurate views of the finger with the aid of a support to hold the proximal plane of the finger tip parallel to the $x$-rays. For this purpose a metal support or shelf was constructed to hold comfortably the partially flexed hand with the finger to be $x$-rayed extending over the shelf to free it from deforming pressure and its axis perpendicular to the rays six feet from the tube. The $x$-ray film is held in a rigid support immediately behind the finger. In lateral views taken in this manner the soft tissues are well outlined and the skin creases used to define the limits of the finger tip easily identified. A straight line connecting the dorsal and palmar crease then delimits the bone segment to be measured. The length of this segment may then be determined with a dividers and laid off upon the bone segment of an $A P$ view obtained in a similar manner.

TABLE I

Representative determinations on five subjects

\begin{tabular}{|c|c|c|c|c|c|c|c|}
\hline $\begin{array}{l}\text { Sub- } \\
\text { ject }\end{array}$ & $\boldsymbol{A}$ & $a$ & $L$ & $T$ & $\begin{array}{c}\text { Calcu- } \\
\text { lated } \\
\text { bone } \\
\text { volume }\end{array}$ & $\mid \begin{array}{c}\text { Deter- } \\
\text { mined } \\
\text { total } \\
\text { volume }\end{array}$ & $\begin{array}{l}\text { Soft tissue } \\
\text { volume (Total } \\
\text { volume minus } \\
\text { bone volume) }\end{array}$ \\
\hline $\begin{array}{l}\mathrm{T} \\
\mathbf{O} \\
\mathrm{J} \\
\mathbf{S} \\
\mathbf{B}\end{array}$ & $\begin{array}{r}\text { sq. mm. } \\
179.3 \\
113.5 \\
165.7 \\
128.3 \\
142.5\end{array}$ & \begin{tabular}{|r} 
sq. $\mathrm{mm}$. \\
109.6 \\
79.0 \\
99.9 \\
78.7 \\
90.9
\end{tabular} & $\begin{array}{l}m m . \\
22.7 \\
18.1 \\
22.6 \\
18.6 \\
20.7\end{array}$ & $\mid$\begin{tabular}{l|}
$m m$. \\
4.83 \\
4.36 \\
4.42 \\
4.23 \\
4.39
\end{tabular} & $\begin{array}{l}c c . \\
0.827 \\
0.472 \\
0.069 \\
0.518 \\
0.598\end{array}$ & \begin{tabular}{|c|}
$c c$. \\
5.634 \\
3.501 \\
4.667 \\
4.453 \\
4.466
\end{tabular} & $\begin{array}{c}c c . \\
4.807 \\
3.029 \\
3.968 \\
3.935 \\
3.868\end{array}$ \\
\hline
\end{tabular}

